\title{
Scaling properties and spatial organization of snow depth fields in sub-alpine forest and alpine tundra
}

\author{
Ernesto Trujillo, ${ }^{1}$ Jorge A. Ramírez ${ }^{1 *}$ and Kelly J. Elder ${ }^{2}$ \\ ${ }^{1}$ Department of Civil and Environmental Engineering, Colorado State University, Fort Collins, CO 80523-1372, USA \\ ${ }^{2}$ Rocky Mountain Research Station, USDA Forest Service, 240 West Prospect Road, Fort Collins, CO 80526, USA
}

\begin{abstract}
:
This paper reports on a study analysing the spatial distribution functions, the correlation structures, and the power spectral densities of high-resolution LIDAR snow depths $(\sim 1 \mathrm{~m})$ in two adjacent $500 \mathrm{~m} \times 500 \mathrm{~m}$ areas in the Colorado Rocky Mountains, one a sub-alpine forest the other an alpine tundra. It is shown how and why differences in the controlling physical processes induced by variations in vegetation cover and wind patterns lead to the observed differences in spatial organization between the snow depth fields of these environments. In the sub-alpine forest area, the mean of snow depth increases with elevation, while its standard deviation remains uniform. In the tundra subarea, the mean of snow depth decreases with elevation, while its standard deviation varies over a wide range. The two-dimensional correlations of snow depth in the forested area indicate little spatial memory and isotropic conditions, while in the tundra they indicate a marked directional bias that is consistent with the predominant wind directions and the location of topographic ridges and depressions. The power spectral densities exhibit a power law behaviour in two frequency intervals separated by a break located at a scale of around $12 \mathrm{~m}$ in the forested subarea, and $65 \mathrm{~m}$ in the tundra subarea. The spectral exponents obtained indicate that the snow depth fields are highly variable over scales larger than the scale break, while highly correlated below. Based on the observations and on synthetic snow depth fields generated with one- and two-dimensional spectral techniques, it is shown that the scale at which the break occurs increases with the separation distance between snow depth maxima. In addition, the breaks in the forested area coincide with those of the corresponding vegetation height field, while in the tundra subarea they are displaced towards larger scales than those observed in the corresponding vegetation height field. Copyright @ 2009 John Wiley \& Sons, Ltd.
\end{abstract}

KEY WORDS snow depth; self-affinity; scaling; fractals; power spectrum; synthetic generation

Received 8 May 2008; Accepted 5 January 2009

\section{INTRODUCTION}

Identifying and characterizing the spatial and temporal variations of snow cover properties (e.g. snow depth, snow density, and snow water equivalent (SWE)) and the relationships between such variability and environmental and hydro-meteorological variables is of importance in hydrology and other applications. Better understanding of these relationships allows for improvements in snowmelt modelling (Luce et al., 1998; Liston and Sturm, 1998; Liston, 1999; Greene et al., 1999), interpolation of point measurements (Elder et al., 1998; Erxleben et al., 2002; Erickson et al., 2005), downscaling of remote sensing data and model results (McGinnis, 2004; Weitzenkamp et al., 2008), subgrid scale parameterizations (Luce et al., 1999; Liston, 2004), and design strategies for measuring and monitoring snow properties (Xu et al., 1993).

One of the most common approaches for such characterization has consisted of determining the statistical relationships between snow properties and topographic and meteorological variables such as elevation, slope, aspect, wind and radiation (Evans et al., 1989; Hosang and Dettwiler, 1991; Elder et al., 1991, 1995, 1998; Blöschl and

\footnotetext{
* Correspondence to: Jorge A. Ramírez, Department of Civil and Environmental Engineering, Colorado State University, Fort Collins, CO 80523-1372, USA. E-mail: ramirez@engr.colostate.edu
}

Kirnbauer, 1992; Erxleben et al., 2002; Winstral et al., 2002; Erickson et al., 2005). More recently, increasing attention has been given to the characterization of the scale invariance of snow properties such as depth (Shook and Gray, 1994, 1996 and 1997; Kuchment and Gelfan, 2001; Arnold and Rees, 2003; Deems et al., 2006; Trujillo et al., 2007), SWE (Shook and Gray, 1997), and snow-covered area (SCA) (e.g., Shook et al., 1993; Shook and Gray, 1997; Blöschl, 1999; Granger et al., 2002). These studies have been based on the application of variogram and semi-variogram analyses and spectral techniques previously applied to other variables such as rainfall (Lovejoy and Schertzer, 1985; Tessier et al., 1993; Over, 1995; Over and Gupta, 1996; Marsan et al., 1996; Kang and Ramírez, 2001), soil moisture (Rodríguez-Iturbe et al., 1995), topography (Mandelbrot, 1967, 1982; Brown, 1987; Turcotte, 1987, 1989; Huang and Turcotte, 1989), and steady-state and transient infiltration rates (Meng et al., 1996).

Among the snow cover properties, snow depth has received most of the attention because it is one of the most spatially variable, and also because it is one of the easiest to measure. Several different techniques have been used for the study of the scale invariance of snow depth, from the analysis of the dependence of the standard deviation of snow depth on sampling 
distance, to more complex techniques such as variogram and spectral analyses. The types of measurements used range from point data along linear transects obtained in winter field campaigns to high-resolution remote sensing measurements that provide snow depth information over areas of the order of $1 \mathrm{~km}^{2}$. The summary presented below presents the recent progression of the knowledge provided by these studies, from the first studies by Shook and Gray $(1994,1996)$, to the latest findings by Trujillo et al. (2007).

Shook and Gray $(1994,1996)$ analysed the standard deviation of snow depth along linear transects in prairie and Arctic environments as a function of sample distance, covering distances of up to $1200 \mathrm{~m}$. Their results indicate a power-law type increase of the standard deviation up to sampling distances of the order of $20 \mathrm{~m}$, after which the relationship is asymptotic to a slope of 0.06 in the $\log -\log$ domain. Shook and Gray (1996) defined a 'cut-off' length as the point of intersection between the initial slope and a horizontal tangent to the end of the curve in the $\log -\log$ plot of standard deviation versus sample distance. This definition is used to compare the scale at which the break occurs in different environments, extending the analysis to transects in two other areas with variations in elevation range. Cut-off lengths between $30 \mathrm{~m}$ and $500 \mathrm{~m}$ were obtained for the three environments. Shook and Gray (1996) hypothesized that the autocorrelation structure of snow depth in one of their study areas used for agriculture (stubble) was due to the formation of dunes of snow (i.e. snow drifts), stating that the autocorrelation structure caused by a dune must terminate at scales greater than the length of a dune. They describe the cutoff length as an index of the upper limit of the fractal structure of the fields, and hypothesize that such a cutoff length is established primarily by topography in the absence of major changes in vegetation.

Shook and Gray (1996) also suggest that the magnitude of the cutoff length may be related to the degree of large-scale topographic relief, based on an observed increase in the cutoff length with relief for three snow depth transects in three different locations. Additionally, Shook and Gray (1996) tested the influence of large-scale trends in snow depth on the cutoff length by de-trending two snow depth transects of about $150 \mathrm{~m}$ and $170 \mathrm{~m}$ in length. The de-trending consisted of subtracting a linear and a polynomial function of horizontal distance. Before subtracting these trends, the $\log -\log$ plots of standard deviation of snow depth versus sampling distance demonstrated similar slopes with no breaks for both of the profiles. Once de-trended, the standard deviation of the profiles displayed cutoff lengths at approximately $30 \mathrm{~m}$, with slopes similar to those obtained for the original data below the cutoff length, and a flatter function above the cutoff length. From the decrease in the cutoff length produced by the de-trending of the profiles, Shook and Gray (1996) conclude that the autocorrelation of snow depth is due to both small-scale and large-scale surface features, and that the effect of large-scale features is to increase the cutoff length. On the basis of the similarities of the cutoff lengths obtained for the de-trended data of the fallow and stubble transects, they also suggest that the magnitude of the cutoff distance is relatively insensitive to land use, and that the cutoff length is a measure of the effects of topographic variability on snow accumulation.

Recently, a high-definition $(\sim 1.5 \mathrm{~m}$ separation between observations) dataset of spatially distributed snow depths has become available as part of NASA's Cold Land Processes Experiment (CLPX). The dataset consists of airborne LIght Detection And Ranging (LIDAR) measurements of snow depth, topography and elevation returns to the top of vegetation for nine $1 \mathrm{~km}^{2}$ intensive study areas (ISAs) located in the state of Colorado (USA) (see the following section for more details). These data have been used in two recent studies of the scaling characteristics of the spatial distribution of snow depth (Deems et al., 2006; Trujillo et al., 2007) focusing on determining the control that vegetation, topography and winds exert on such scaling characteristics.

Deems et al. (2006) analysed the variograms of the LIDAR measurements of snow depth, topography and vegetation topography (i.e. elevation + vegetation height) of three of the nine $1 \mathrm{~km}^{2}$ study areas (i.e. Buffalo Pass, Walton Creek, and Alpine ISAs), in which the spatial distribution of snow depth is strongly influenced by wind redistribution of snow. From the observed log-log linearity of the variograms, they infer fractal behaviour in the elevation, vegetation topography and snow depth datasets. Their analyses seem to indicate the existence of two distinct scale regions with fractal distributions for the snow depth and vegetation topography datasets, separated by a scale break whose location varies between $15 \mathrm{~m}$ and $40 \mathrm{~m}$ for snow depth, and between $31 \mathrm{~m}$ and $56 \mathrm{~m}$ for vegetation topography, similar to the results obtained by Shook and Gray $(1994,1996)$, Kuchment and Gelfan (2001) and Arnold and Rees (2003). The fractal dimensions obtained for snow depth are of the order of 2.5 for the shorter scale range and 2.9 for the longer scale range. From these values, Deems et al. (2006) speculate that for the short range there is a balance between highand low-frequency variations, while at larger distances the distribution of snow depth approaches a spatially random distribution. They also speculate that the scale breaks in the snow depth variograms indicate a switch from a pattern dominated by short-range vegetation variability to one predominately influenced by longerrange variations in terrain, based on similarities in the behaviour of the variograms of vegetation topography. Deems et al. (2006) also suggest that the location of the scale break might be related to the overall terrain relief on the basis of an overall increase in the location of the scale break with relief for the three study areas, supporting the hypothesis first proposed by Shook and Gray (1996). They also state that the process change revealed in the terrain-vegetation (topography + vegetation height) data potentially influences the scaling behaviour of snow depth patterns, given that the scale break separating the two fractal regions in the terrain-vegetation distributions 
is of the same order of magnitude as the scale break observed in the snow depth data. Finally, from relatively small variations of the fractal dimensions for different directions of the order of $0 \cdot 1$ in the snow depth, Deems et al. (2006) conclude that such variations show a strong qualitative relationship to prevailing winds and largescale topographic orientation.

Trujillo et al. (2007) used a similar dataset that includes data from five of the nine $1 \mathrm{~km}^{2}$ study areas of the CLPX, two of them included in the study by Deems et al. (2006), covering a wider range of environments with differences in topography, vegetation and meteorological characteristics. In their study, Trujillo et al. analysed the power spectral densities of the $1 \mathrm{~km}^{2}$ raster fields of snow depth, topography, topography + vegetation height, and vegetation height, comparing the results obtained for each of these fields and identifying all relationships between them. They complemented their study with an analysis of maximum wind speeds and directions, and of the separation distance between peaks in the snow depth and vegetation height profiles. Also, they compared the spectral characteristics (e.g. spectral exponents and scale breaks) to wind patterns in search of any relationship between the variables. Their analyses show that the spectral densities of snow depth and vegetation height exhibit a similar bilinear power-law behaviour separated by scale breaks located at wavelengths of the order of metres to tens of metres. However, a comparison of the location of the scale breaks in the snow depth spectra and the corresponding vegetation height spectra reveals that the scale breaks in the snow depth scaling coincide with those of the vegetation height fields only in environments in which the spatial variability of snow depth is controlled by canopy interception of snowfall, while the break in the snow depth scaling is displaced towards larger scales than those of the corresponding vegetation height fields in environments with a strong influence of wind redistribution of snow. These results are in contrast to those of Deems et al. (2006). Trujillo et al. (2007) give explanation to the relationship between the spectral properties of snow depth and vegetation height in environments in which canopy interception of snow is dominant by comparing the empirical probability distributions of the separation distance between peaks in the snow depth and vegetation height profiles of the fields. This comparison shows that the separations between peaks in the profiles of both, vegetation height and snow depth, exhibit similar statistical characteristics as a sign of similar characteristic scales in both fields. They state that such similarities are a consequence of the effect of canopy interception of snow in the distribution of snow depth given that the location of the peaks (maxima) in the vegetation height fields (coincident with the location of trees) coincides with the location of low points (minima) in the snow depth fields in environments in which the distribution of snow depth is strongly influenced by canopy interception of snow. On the other hand, Trujillo et al. (2007) show the control that wind patterns exert on the spectral characteristics of snow depth in environments in which wind redistribution of snow is dominant by comparing the distributions of wind direction with the variation of the spectral exponents and scale breaks with direction. Such comparisons reveal a strong relationship between the spectral exponent of the low-frequencies and the location of the scale break with the predominant wind directions as a sign of the influence of wind patterns on the characteristics of the spatial variability of snow depth in such environments. The differences observed in the spectral characteristics (i.e. spectral exponents and scale break) of the snow depth fields between the different environments and the relationship of such characteristics to vegetation indicate that land use plays an important role in determining the scaling characteristics of the spatial distribution of snow depth, especially in environments in which canopy interception of snow depth is dominant, contrary to what was proposed by Shook and Gray (1996). Furthermore, Trujillo et al. (2007) demonstrated that the location of the scale break is a measure of the separation distance between high points or peaks in the snow depth surface, and that the characteristics of the variations in the snow depth fields change above and below such characteristic scales. These results corroborate Shook and Gray's (1996) suggestions that the change in the autocorrelation structure of snow depth in environments with the influence of wind redistribution is caused primarily by the formation of dunes (i.e., snowdrifts), and that the autocorrelation caused by a dune must terminate at scales greater than the length of the dune. Contrary to the suggestion by Deems et al. (2006) with respect to the influence of topographic relief on the location of the scale break, Trujillo et al. (2007) found no clear relationship between the two variables, as the location of the scale break was demonstrated to be related to other characteristics of the environments.

In this study, differences in the spatial organization of snow depth between a sub-alpine forest and an alpine tundra environment are described and explained based on the analysis of spatial distribution functions, correlation functions, and power spectral densities of high-resolution LIDAR measurements $(\sim 1 \mathrm{~m})$ obtained within two adjacent $500 \mathrm{~m} \times 500 \mathrm{~m}$ study areas located in the Colorado Rocky Mountains. Both of the areas are located in the Alpine ISA of the and present similar topographic characteristics (e.g. slope and aspect), but different vegetation characteristics and wind patterns. The analysis is complemented by the application of spectral techniques for generating synthetic one-dimensional profiles and twodimensional fields that reproduce the scaling characteristics (i.e., spectral exponents and scale breaks) observed in the snow depth fields.

\section{FIELD DESCRIPTION AND DATASET}

The data used in this study were collected as part of the CLPX in 2003 (Cline et al., 2001). The CLPX was a cooperative effort by NASA, NOAA and other government agencies and universities designed to advance 

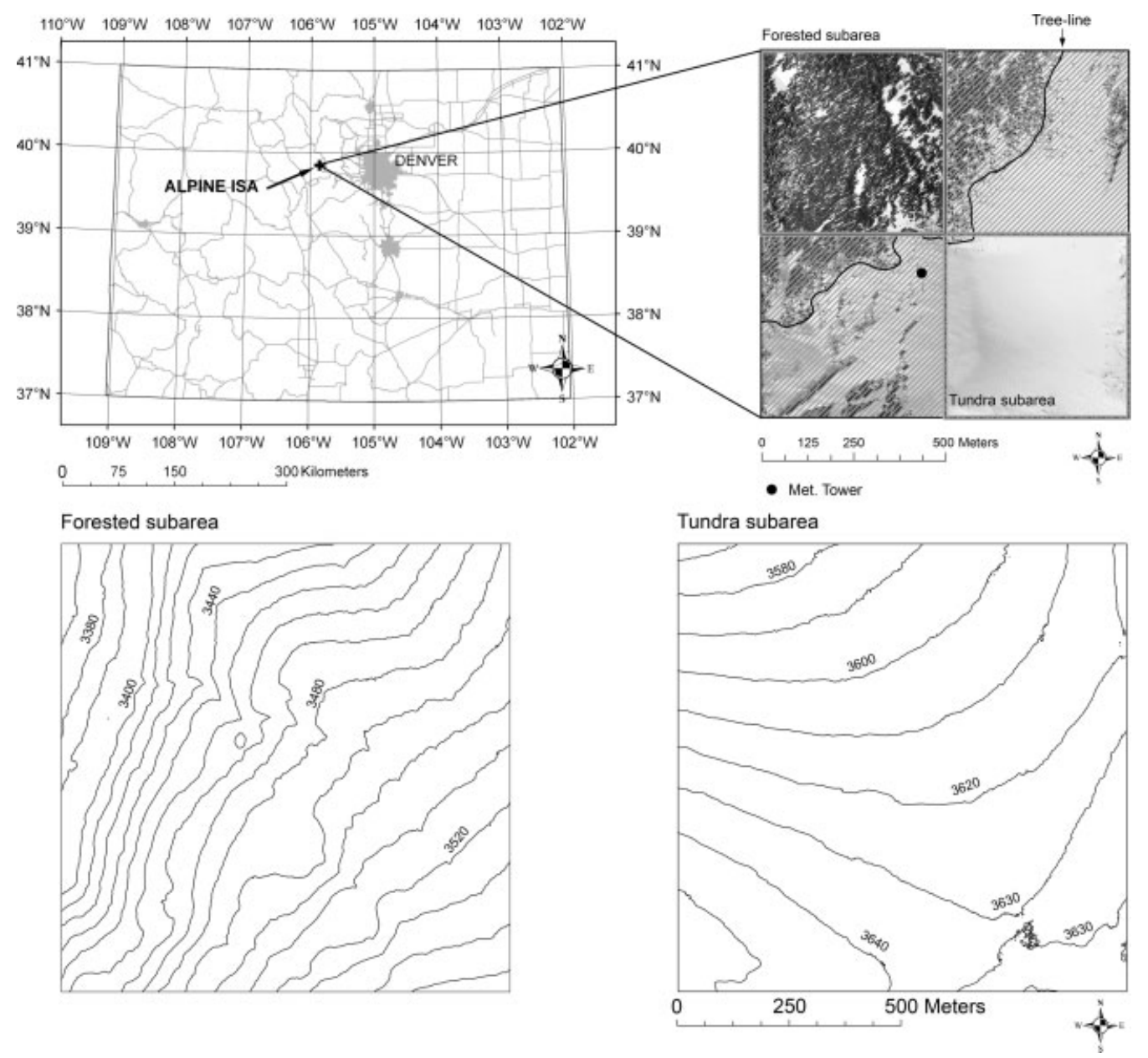

Figure 1. Location of the Alpine Intensive Study Area (ISA) of the CLPX in the state of Colorado. The detail shows the aerial photography of the ISA taken on 8 April 2003. Also, boundaries for the forested and the tundra subareas are included. The location of the meteorological tower above the tree-line is marked by the black dot. The topographic contours of the subareas are shown in the bottom panels

the understanding of the terrestrial cryosphere, providing information to address questions on cold land processes, spatial and temporal variability of the snow cover, and uncertainty of remote sensing measurements and models (Cline et al., 2001). The study area of the CLPX comprises a nested array of study areas at five different scale levels in the state of Colorado and a small portion of southern Wyoming. The two first levels correspond to one large and one small regional study area of $3.5^{\circ} \times 4.5^{\circ}$ and $1.5^{\circ} \times 2.5^{\circ}$, respectively. Three Meso-cell study areas (MSAs) of $25 \mathrm{~km} \times 25 \mathrm{~km}$ and nine $1 \mathrm{~km} \times 1 \mathrm{~km}$ ISA make up the third and fourth scale levels, respectively. The last scale level corresponds to one local-scale observation site (LSOS) of 1 ha. This study focuses on the Alpine ISA. Such focus is motivated by the existence of alpine tundra and sub-alpine forest environments within this ISA, each exhibiting different characteristics in the spatial organization of the snow cover. The hypothesis is that those differences result from differences in the controlling physical processes induced by variations in vegetation cover and, consequently, the control of wind patterns on the spatial organization of snow depth.

The Alpine ISA is a high-altitude area located in the Fraser MSA in the Colorado Rocky Mountains
(Figure 1). This ISA is located in the transition between the sub-alpine and the alpine tundra environments, with elevations that range between $3364 \mathrm{~m}$ a.s.1. and $3676 \mathrm{~m}$ a.s.l. The tree-line that separates the sub-alpine and the tundra environments is located at about $3565 \mathrm{~m}$ a.s.1., with the lower portion covered by a dense coniferous forest, and the higher portion covered by short tundra vegetation (Figure 1). Most of the area is on a northwest facing slope, with little aspect variation (Figure 2a). Slopes in the ISA are moderate, with $94 \%$ of the area with slope angles of less than $30^{\circ}$, and an average slope angle of $15^{\circ}$ (Figure 2b). Terrain features such as aspect and slope exhibit little variation within the ISA, and the main difference between the two environments is the vegetation cover. This difference translates into a difference in wind patterns due to the shielding effect that the trees offer.

The dataset used for this study consists of LIDAR elevation returns (filtered to bare ground/snow, and filtered to top of vegetation), elevation contours $(0.5 \mathrm{~m})$, and snow depth contours $(0.1 \mathrm{~m})$ (Miller, 2003; Cline et al., 2008). These data were processed from the LIDAR elevation returns with an average horizontal spacing of $1.5 \mathrm{~m}$ 

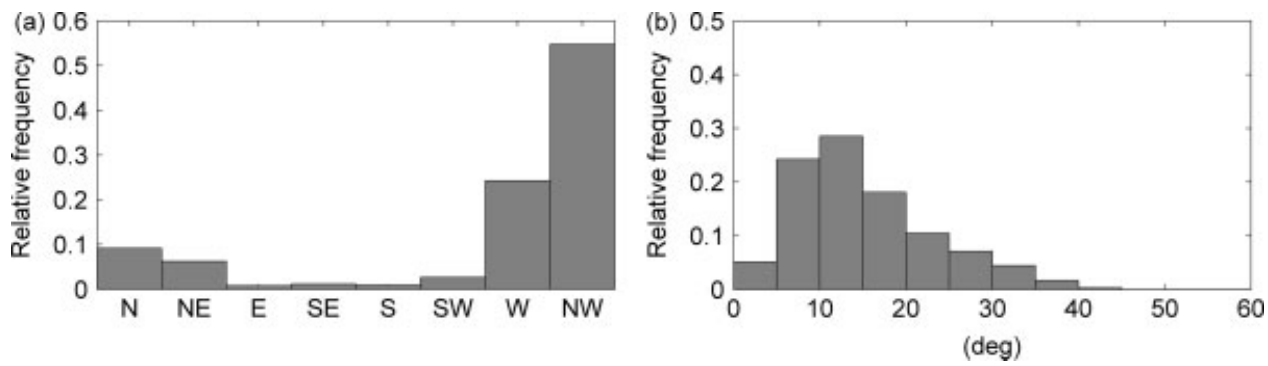

Figure 2. Histograms of (a) aspect and (b) slope angle for the entire Alpine ISA

(a)

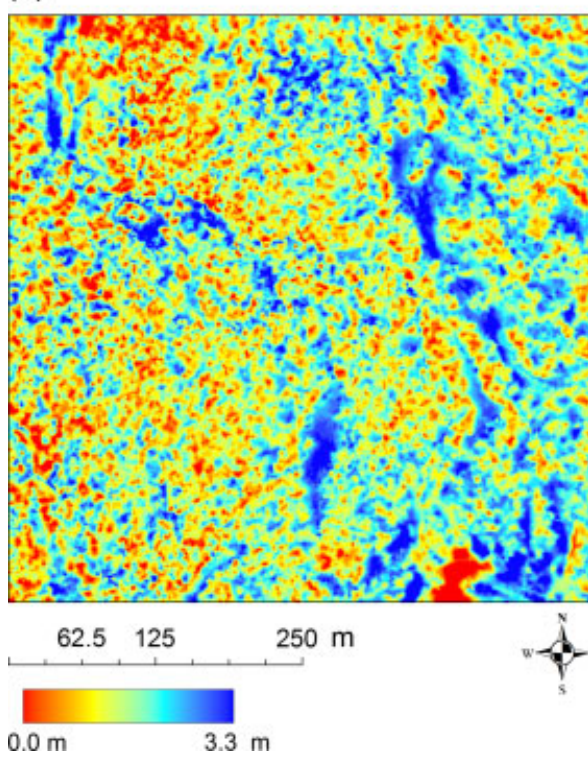

(b)

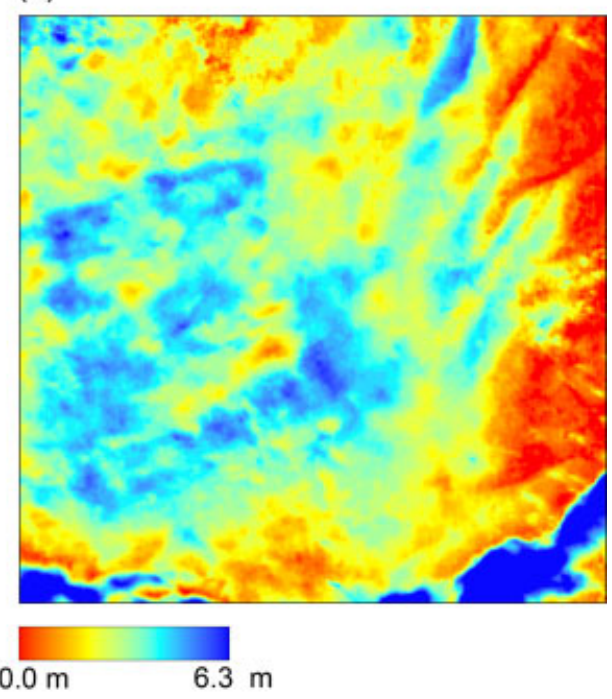

Figure 3. Snow depth fields derived from LIDAR for the forested (a) and the tundra (b) subareas

and vertical tolerance of $0.05 \mathrm{~m}$. The snow depth contours were obtained by subtracting the two topographic surfaces corresponding to snow-covered conditions close to maximum accumulation (8 April 2003) and no-snow conditions (18 September 2003). The contour maps were used to generate triangulated irregular network (TIN) surfaces of the fields in ArcGIS, which then were converted to rasters of 1024 by 1024 grid cells covering the entire $1 \mathrm{~km}^{2}$ area with a grid spacing of approximately $1 \mathrm{~m}$ for snow depth, bare ground elevations (topography), and elevation to the top of vegetation (topography + vegetation). Two subareas $500 \mathrm{~m}$ by $500 \mathrm{~m}$ were selected within the ISA (Figure 1), one being a forested environment the other an alpine tundra environment. The resulting snow depth fields for these study subareas are presented in Figure 3.

In addition, wind data collected as part of the CLPX at a meteorological tower located in the alpine portion of the ISA (Figure 1) are also used. The data correspond to wind speeds and directions at $1 \mathrm{~m}$ above maximum expected snow depth (lower sensor) and $10 \mathrm{~m}$ above the ground (upper sensor) for the period October 2002 to April 2003, chosen to represent the meteorological characteristics between the first snowfalls and the time at which the LIDAR snow depths were obtained. The empirical distributions of maximum wind speed at the lower and upper sensors are shown in Figure 4, and the distributions of wind direction are shown in Figure 5. Given that snow redistribution due to wind is only likely to occur when the air temperature is below freezing, only maximum wind speeds and directions for 10 min intervals with air temperature less than $0{ }^{\circ} \mathrm{C}$ were analysed. Average maximum wind speeds are $7.2 \mathrm{~m} \mathrm{~s}^{-1}$ at the lower sensor, and $8.3 \mathrm{~m} \mathrm{~s}^{-1}$ at the upper sensor, and maximum wind speeds exceed a threshold of $5 \mathrm{~m} \mathrm{~s}^{-1} 70 \%$ of the time at the lower sensor, and $76 \%$ of the time at the upper sensor. Such values are evidence of strong wind regimes, with potential for significant redistribution of snow when the snow surface is exposed. Threshold wind speeds (at $z=10 \mathrm{~m}$ ) for snow transport have been measured to range between $4 \mathrm{~m} \mathrm{~s}^{-1}$ and $11 \mathrm{~m} \mathrm{~s}^{-1}$ for dry snow conditions, and between $7 \mathrm{~m} \mathrm{~s}^{-1}$ and $14 \mathrm{~m} \mathrm{~s}^{-1}$ for wet snow conditions ( $\mathrm{Li}$ and Pomeroy, 1997). The predominant winds in the area flow from the north-west, similar to the predominant topographic aspect of the area (Figure 2a).

\section{SPATIAL ANALYSIS}

\section{Spatial distributions}

The histograms of snow depth for the forested and tundra subareas are shown in Figure 6, and summary statistics are presented in Table I. The distribution of snow 


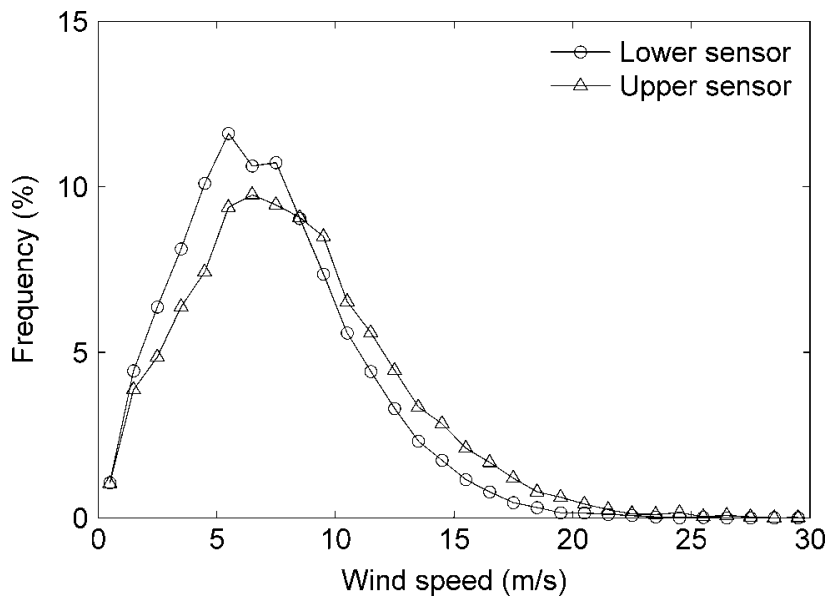

Figure 4. Empirical distribution functions of maximum wind speed every $10 \mathrm{~min}$ for the period October 2002-April 2003 measured at $1 \mathrm{~m}$ above the maximum expected snow depth (lower sensor) and $10 \mathrm{~m}$ above the ground (upper sensor). Only data for intervals with air temperature lower than $0{ }^{\circ} \mathrm{C}$ are included. Average speeds are $7.2 \mathrm{~m} \mathrm{~s}^{-1}$ at the lower sensor, and $8.3 \mathrm{~m} \mathrm{~s}^{-1}$ at the upper sensor

depth in the forested subarea is approximately Gaussian, with snow depths between $0 \mathrm{~m}$ and $3.3 \mathrm{~m}$, and a mean of $1.62 \mathrm{~m}$. On the other hand, the distribution for the tundra subarea resembles a negatively skewed truncated distribution, with snow depths between $0 \mathrm{~m}$ and $6.3 \mathrm{~m}$, and a mean of $1.20 \mathrm{~m}$. The standard deviation is greater in the tundra subarea, with a value of $0.65 \mathrm{~m}$, compared with $0.33 \mathrm{~m}$ in the forested subarea. When mean and

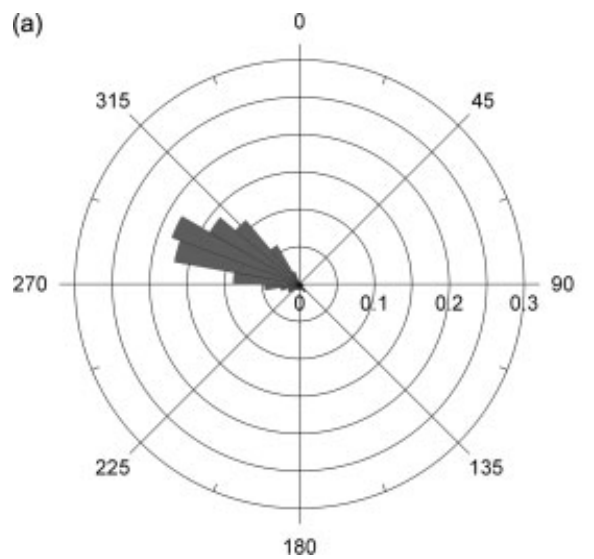

standard deviation are analysed as a function of elevation (Figure 7), additional differences can be observed. In the forested portion, the mean snow depth increases at an average rate of $2.0 \mathrm{~m}$ per $1000 \mathrm{~m}$ elevation. The trend reverses in the tundra portion, where the mean snow depth decreases with elevation from about $1.8 \mathrm{~m}$ at $3555 \mathrm{~m}$ a.s.1. to almost zero at $3676 \mathrm{~m}$ a.s.1., although with large variations in the overall trend. The standard deviation also shows a clear change in behaviour above the tree-line. Below the tree-line, the standard deviation remains relatively constant with elevation, with values that range between $0.3 \mathrm{~m}$ and $0.4 \mathrm{~m}$, while above the tree-line in the tundra subarea, there is an overall increase with values that are highly variable and with maxima close to $1.6 \mathrm{~m}$, indicating larger variations around the mean in the tundra environment.

The differences in the statistical characteristics of the two snow depth fields can be explained by the differences between the two environments. The effect of the strong winds on the spatial distribution of snow depth is conditioned by the vegetation characteristics, as confirmed by

Table I. Snow depth statistics in the forested and tundra subareas. All values but the coefficient of variation (CV) are in metres

\begin{tabular}{lccccc}
\hline & Mean & Std. Dev. & CV & Min. & Max. \\
\hline Forested & 1.62 & 0.33 & 0.20 & 0.0 & 3.3 \\
Tundra & 1.20 & 0.65 & 0.54 & 0.0 & 6.3 \\
\hline
\end{tabular}

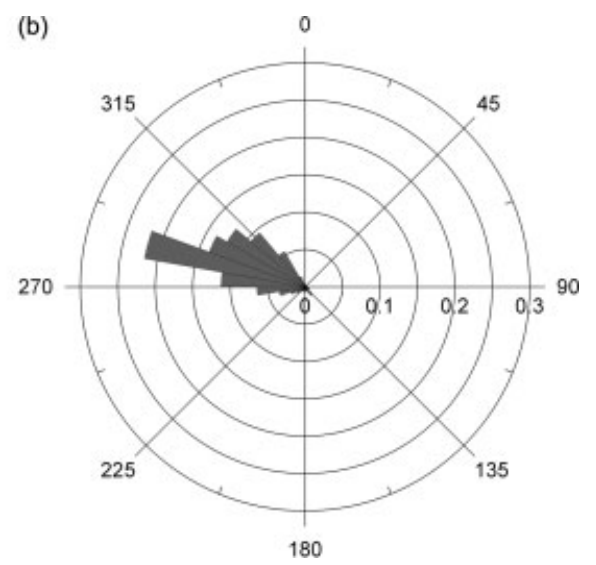

Figure 5. Distributions of mean wind direction for $10 \mathrm{~min}$ intervals for the period October 2002-April 2003 measured at (a) $1 \mathrm{~m}$ above the maximum expected snow depth (lower sensor) and (b) $10 \mathrm{~m}$ above the ground (upper sensor). Data only for intervals with air temperature lower than $0{ }^{\circ} \mathrm{C}$. The radial scale corresponds to the relative frequency. The distributions shown were obtained for the dataset without a minimum threshold wind speed. Similar distributions are obtained for wind speeds above thresholds of $4 \mathrm{~m} \mathrm{~s}^{-1}$ and $5 \mathrm{~m} \mathrm{~s}^{-1} .0^{\circ}$ corresponds to the north direction
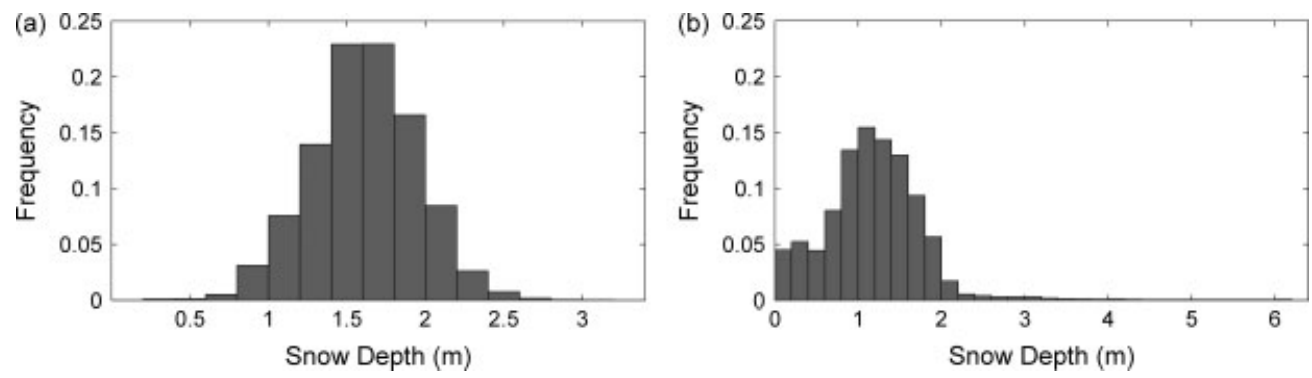

Figure 6. Histograms of snow depth for the forested (a) and tundra (b) subareas. A summary of the statistics for these distributions is presented in Table I 


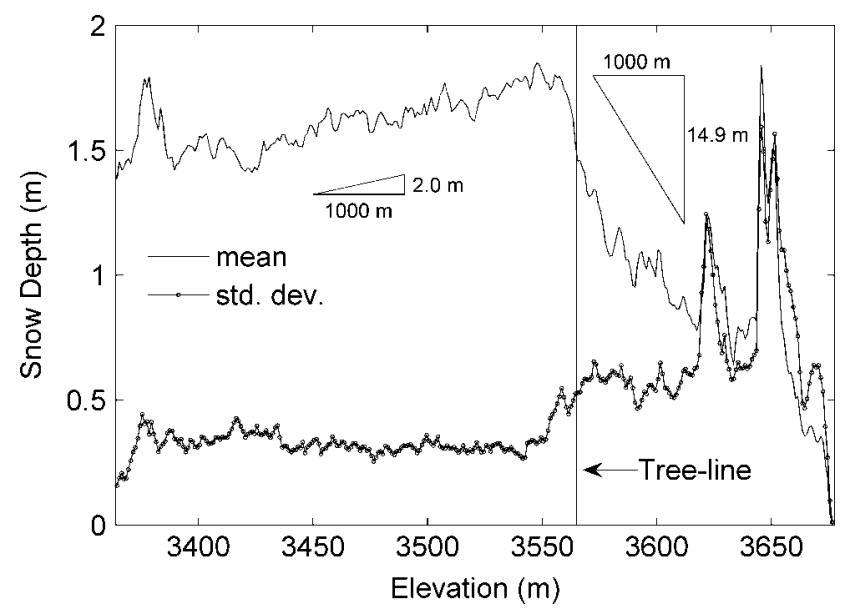

Figure 7. Mean and standard deviation of snow depth as a function of elevation obtained for the entire Alpine ISA. The figure illustrates the significant change in the characteristics of the snow cover above the tree-line, located at about $3565 \mathrm{~m}$ a.s.1

the patterns that can be observed in Figure 3. In the tundra environment above the tree line, the snow depth field is characterized by a pattern of snowdrifts and scour areas aligned with the location of ridges and depressions and perpendicular to the predominant wind direction, while the snow depth field in the forested subarea exhibits a pattern dominated by small-scale variability consistent with the location of trees, with little or no sign of snow redistribution by wind due to the shielding effect of the forest. The relatively constant standard deviation with elevation below the tree-line is a sign of similar characteristics in the spatial variability of snow depth throughout the forested subarea due to the relatively uniform characteristics of the vegetation. On the other hand, the decreasing trend in the mean snow depth with elevation in the tundra subarea is evidence of the effect of snow redistribution by wind. Due to the predominant wind directions and the overall terrain aspect, the snow of the tundra subarea is transported uphill, not only leading to the formation of snowdrifts and eroded areas, but also blowing a significant portion of the snow out of the ISA to be deposited on the lee side of the mountain, located to the southeast of the ISA. Also, the redistribution of snow by wind induces losses associated with the sublimation of blowing snow, which have been measured to account for annual losses from $9 \%$ to $47 \%$ of the annual precipitation (Benson, 1982; Pomeroy and Gray, 1995; Essery et al., 1996; Liston and Sturm, 1998; Pomeroy et al., 1998). These processes cause a decrease in the mean snow depth above the tree-line, which becomes more evident as elevation increases, as the distance from the tree-line increases (commonly referred to as fetch), and the eroding and transport potential of the wind also increases. Similarly, the overall increase in the standard deviation above the tree-line and the large variations of the mean and standard deviation with elevation are evidence of the pattern of snow drifts and scour areas throughout the tundra environment that are responsible for the large variations of snow depth around the mean.

\section{Two-dimensional autocorrelation functions}

The two-dimensional autocorrelation functions of snow depth are shown in Figure 8 for lags up to $\pm 100 \mathrm{~m}$ in the $x$ and $y$ directions. The correlation function of snow depth in the forested environment exhibits a rapid decay, reaching values of around 0.2 at lags of the order of $10 \mathrm{~m}$. On the other hand, the correlation function of snow depth in the tundra environment shows a slower decay indicating a smoother surface with longer spatial memory. These results indicate that the variations in snow depth occur over much shorter scales in the forested subarea, which can also be observed in the snow depth fields shown in Figure 3. The two-dimensional correlation function also provides information about the directionality of the snow depth fields in the two environments. The correlation function in the forested environment shows little anisotropy, as the contour lines above a correlation value of 0.3 are concentric and relatively circular, while the correlation function for the tundra environment shows an anisotropic decay that follows a gradient in the northwestern direction (equivalent to the south-eastern gradient). Such directionality in the tundra subarea is consistent with the predominant wind directions (Figure 5) and the overall topographic aspect (Figure 2a). The weakest correlation structure (fastest decay) of the snow depth field in the tundra environment occurs along a direction parallel to the predominant wind direction, while the strongest correlation structure occurs along the direction perpendicular to the predominant wind direction.

\section{One-dimensional and mean two-dimensional power spectra}

Spectral techniques have been used in the study of highly variable processes to determine scaling ranges, spectral slopes, fractal dimensions and Haussdorf exponents. Spectral techniques are applied in this study in two different ways. For the one-dimensional case, onedimensional power spectral densities were obtained separately for each of the west to east $(x)$ rows and each of the north to south $(y)$ columns of the fields, and then averaged over each direction for each of the square subareas. For the two-dimensional case, the mean twodimensional power spectral density was determined as the radial average of the two-dimensional spectral density, determined from the two-dimensional Fourier transform of the fields. The methodologies followed for the oneand two-dimensional spectral analyses presented here are described in detail in Trujillo et al. (2007). This spectral analysis was applied to the fields of snow depth and vegetation height in order to compare the scaling behaviour of the two fields.

The $\log -\log$ plots of the one- and two-dimensional power spectral densities of snow depth are shown in Figure 9. The power spectra of the snow depth fields behave like $k^{-\beta}$ within two scale intervals, each characterized by a different spectral exponent ( $k$ is the wave number divided by the length of the profiles, and it represents the spatial scale or wavelength under consideration, and $\beta$ is the spectral exponent and characterizes 

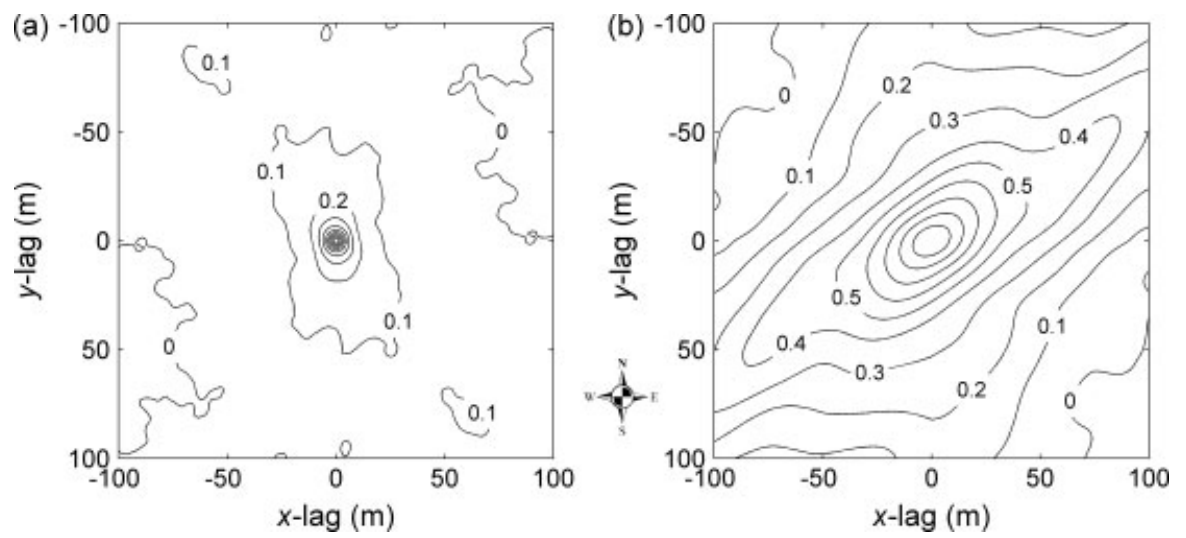

Figure 8. Contour maps of the two-dimensional correlograms of snow depth for (a) the forested subarea, and (b) the tundra subarea
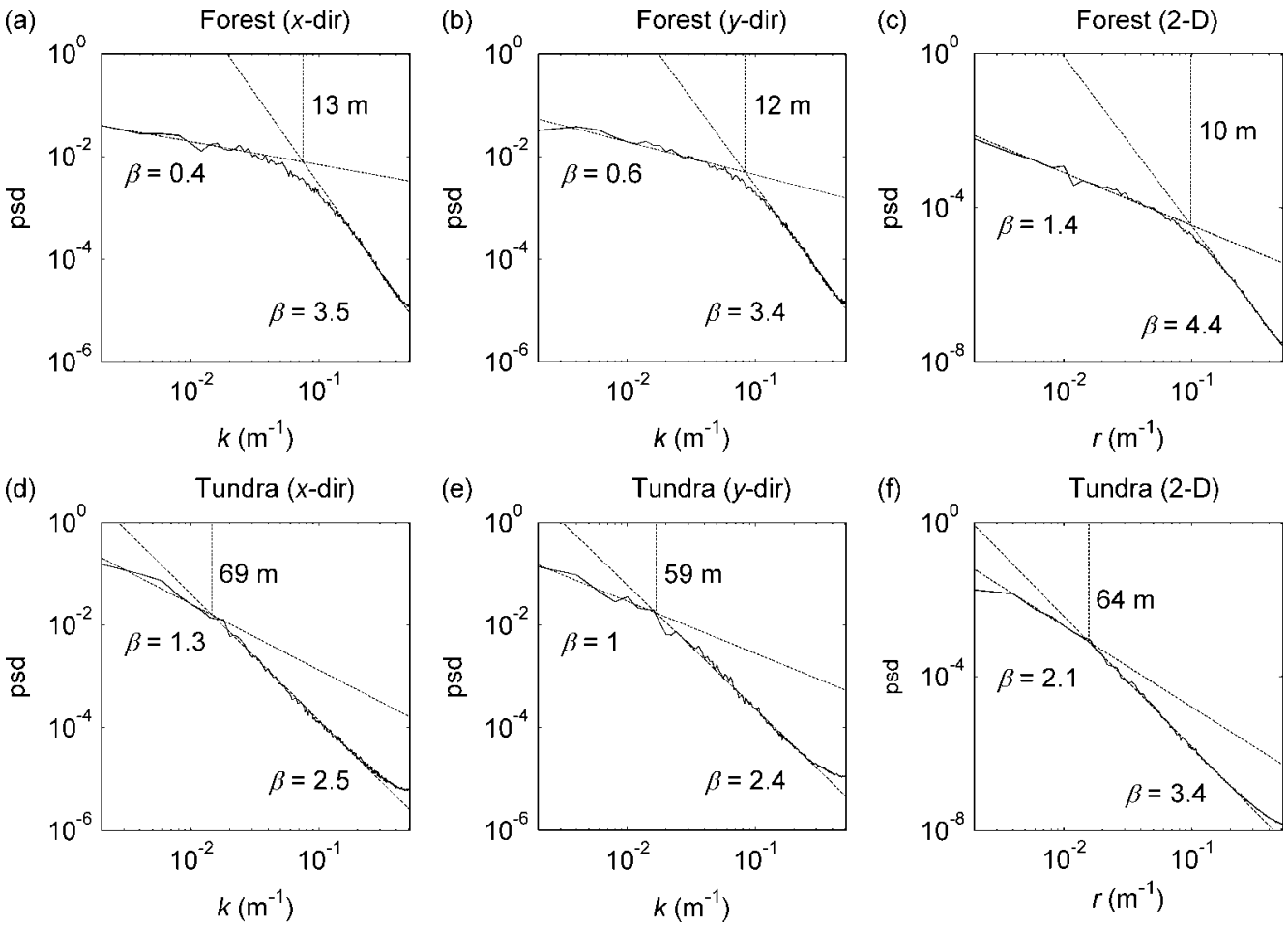

Figure 9. One-dimensional and mean two-dimensional power spectral densities of snow depth for the forested and alpine tundra subareas

the degree of variability). For the one-dimensional case, the spectral exponents in the forested subarea for the low-frequencies interval are 0.4 and 0.6 for the $x$ and $y$ directions, respectively, while they are 3.5 and 3.4 for the $x$ and $y$ directions, respectively, for the high-frequencies interval. The break that separates the two intervals is located at a spatial scale of about $12 \mathrm{~m}$. For the tundra subarea, the low-frequency spectral exponents are 1.3 and 1.0 for the $x$ and $y$ directions, respectively, while they are 2.5 and 2.4 for the high-frequency interval for the $x$ and $y$ directions, respectively. The scale breaks are located at $69 \mathrm{~m}$ and $59 \mathrm{~m}$ for the $x$ and $y$ directions, respectively. The one-dimensional spectral exponents obtained for the low-frequency intervals indicate that for points separated by distances larger than the scale of the break, the corresponding snow depths are weakly correlated. The snow depth profiles are highly variable over scales larger than the scale of the break. On the other hand, the high-frequency spectral exponents indicate that for points that are closer than the break, the corresponding snow depth values are highly correlated. The profiles become smoother below the corresponding break. The change in the characteristics of the variability occurs at scales of the order of $10 \mathrm{~m}$ for the forested subarea and of several tens of metres for the tundra subarea.

For the two-dimensional case, the low- and highfrequency spectral exponents for the snow depth field of the forested subarea are 1.4 and 4.4 , respectively, while they are 2.1 and 3.4 , respectively, for the tundra subarea. The breaks are located at $10 \mathrm{~m}$ for the forested subarea, and at $64 \mathrm{~m}$ for the tundra subarea. The magnitudes of the observed one- and two-dimensional spectral exponents differ by approximately one, as expected theoretically for isotropic fields (Voss, 1985).

The breaks in the one- and two-dimensional spectra of the snow depth fields of the two subareas are located 
within the same range found in the studies of the spatial scale-invariance of snow depth along linear transects (Shook and Gray, 1994, 1996 and 1997; Arnold and Rees, 2003) and snow depth fields (Deems et al., 2006; Trujillo et al., 2007). However, the scale breaks for the snow depth field of the tundra environment are located at larger spatial scales than those of the forested subarea, similar to what was found by Trujillo et al. (2007), indicating longer characteristic scales in the snow depth field of the tundra subarea. This observation is consistent with that observed in the two-dimensional correlation functions (Figure 8).

The last of the spectral analyses explores the scaling properties of the vegetation height fields. This analysis indicates that the power spectra of the vegetation height fields also behave like $k^{-\beta}$ within two frequency intervals, with a low-frequency interval characterized by slopes between 0.5 and 0.8 for the one-dimensional case, and between 1.3 and 1.6 for the two-dimensional case, and a high-frequency interval with slopes between 2.9 and 3.4 for the one-dimensional case, and between 3.7 and 4.0 for the two-dimensional case (Table II). The locations of the breaks in the forested subarea coincide with those of the snow depth field, while in the tundra subarea the breaks occur at scales larger than those observed for the corresponding snow depth field. Therefore, the spatial organization of vegetation height and snow depth are similar in the forested subarea, as the spectral exponents and scale breaks are within the same ranges. Trujillo et al. (2007) obtained similar results from the analysis of the power spectral densities of snow depth and vegetation height in five $1 \mathrm{~km}^{2}$ areas. They showed that the similarities in the spectral properties of the vegetation height and snow depth fields in forested environments are a consequence of canopy interception because the location of the peaks (maxima) in the vegetation height fields (coincident with the location of trees) coincides with the location of low points (minima) in the snow depth fields. The results presented here further confirm the control that vegetation and wind redistribution of snow exert on the spatial scaling characteristics of snow depth.

\section{Synthetic snow depth profiles and fields}

To help understand the implications of the observed one- and two-dimensional power spectra, synthetic snow

Table II. Summary of the spectral characteristics for the vegetation height fields in the forested and tundra subareas

\begin{tabular}{llll}
\hline Forested & $x$ & $y$ & 2-D \\
\hline Low-frequency $\beta$ & $0 \cdot 5$ & $0 \cdot 6$ & $1 \cdot 3$ \\
High-frequency $\beta$ & $3 \cdot 3$ & $3 \cdot 4$ & $\begin{array}{l}4 \cdot 0 \\
\text { Scale break (m) }\end{array}$ \\
& 9 & 10 & 8 \\
\hline Tundra & $x$ & $y$ & 2-D \\
\hline Low-frequency $\beta$ & $0 \cdot 8$ & $0 \cdot 8$ & $1 \cdot 6$ \\
High-frequency $\beta$ & $2 \cdot 9$ & 2.9 & $3 \cdot 7$ \\
Scale break (m) & 14 & 15 & 14 \\
\hline
\end{tabular}

depth profiles and snow depth fields with bilinear spectral densities, and with variations in the spectral exponents and the scale of the break were generated. The spectral generation techniques are presented in the Appendix.

Snow depth profiles. In Figure 10 the effect of the scale of the break is shown with a series of profiles with low-frequency spectral exponent $\left(\beta_{1}\right)$ of 0.0 and a high-frequency spectral exponent $\left(\beta_{2}\right)$ of $3 \cdot 5$. These values allow for separation of a larger-scale interval that is highly variable and uncorrelated from a smaller-scale interval with little variability and high correlation. $T_{b k}$ is the wavelength at which the break occurs, and is inversely related to the wave number $\left(k_{b k}\right)$. The effect of increasing $T_{b k}$ (i.e. reducing $k_{b k}$ ) is illustrated by identifying the peaks or maxima above a zero threshold (circle markers) in the profiles. As $T_{b k}$ increases, the separations between the peaks increase and many of the features (i.e. maxima and minima) in the profiles become less significant. By reducing $k_{b k}$, the number of low-frequency perturbations within the scale interval characterized by spectral exponent $\beta_{1}$ is reduced, and the scales affected by such perturbations are limited to the larger scales. The increase in the high-frequency interval also increases the range of scales characterized by spectral exponent $\beta_{2}$, associated with a stronger correlation structure. The differences in the scale at which the break occurs observed in the one-dimensional spectra of snow imply significantly larger characteristic scales in the alpine tundra subarea, which is also consistent with the slower decay displayed in the correlation function of the alpine tundra subarea (Figure 8b).

Figure 11a shows a series of profiles with $\beta_{1}$ varying between 0.0 and $2 \cdot 0$, constant $\beta_{2}$ of $3 \cdot 5$, and constant
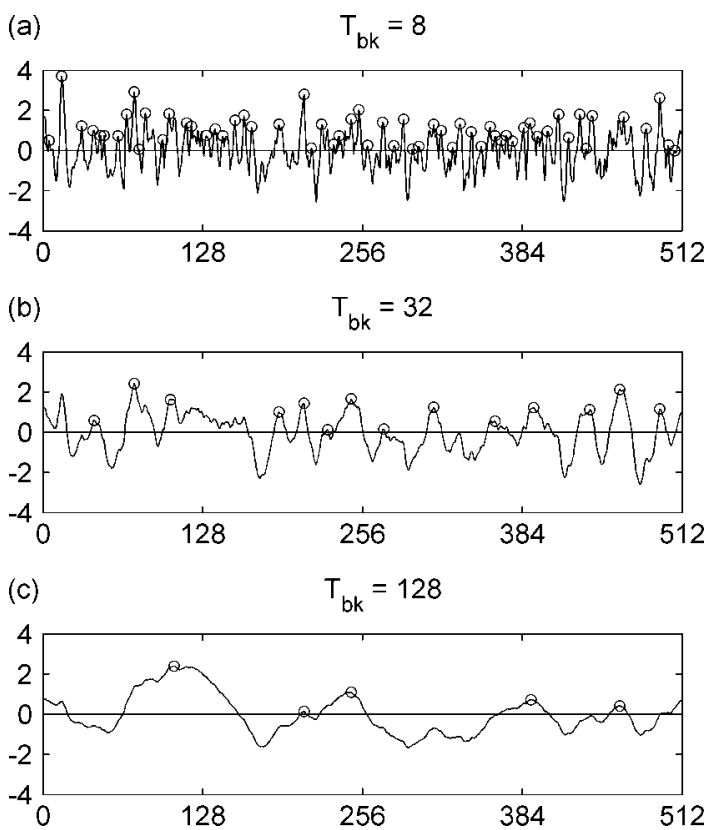

Figure 10. Synthetic profiles with a low-frequencies spectral exponent $\left(\beta_{1}\right)$ of 0.0 and a high-frequencies spectral exponent $\left(\beta_{2}\right)$ of $3 \cdot 5 . T_{b k}$ is the wavelength at which the scale break occurs, and is related to the wave number by $N / k_{b k}$ 
$T_{b k}=32$. The vertical lines in the figure are included as a reference and are spaced at a distance of $T_{b k}$. Overall, the increase in the low-frequencies spectral exponent affects the features of the larger scales, leading to a stronger persistence in the profiles at scales larger than $T_{b k}$. The heights of the profile for points separated by distances larger than $T_{b k}$ become more correlated as $\beta_{1}$ increases. The increase in $\beta_{1}$ also affects the variability of the smaller scales although in a less significant way, because the contribution of perturbations in the high-frequency interval is reduced as the power spectrum in the lowfrequency interval becomes steeper. The low-frequency spectral exponents of snow depth obtained in both of the subareas indicate a weaker correlation structure for scales larger than the corresponding break in the forested subarea with respect to that in the tundra subarea.

Figure 11b shows a series of profiles with a constant low-frequency spectral exponent of $0 \cdot 0$, high-frequency spectral exponents varying between 1.5 and 3.5 , and constant $T_{b k}=32$. As observed, the variability of the profiles for scales smaller than $T_{b k}$ decreases as $\beta_{2}$ increases, while the features at scales larger than $T_{b k}$ are preserved in all of the profiles regardless of the value of $\beta_{2}$. The high-frequency exponent controls the characteristics of the variations for the smaller scales as the exponent controls the contribution of the highfrequency perturbations to the variance. Increasing the exponent implies a faster decay in the contributions, and hence, a smoother profile at scales smaller than $T_{b k}$. According to these observations and the highfrequency exponent values of snow depth for both subareas, the snow depth profiles in the forested subarea show higher correlation structure for scales smaller than the corresponding breaks.

(a) $\beta_{1}=0$
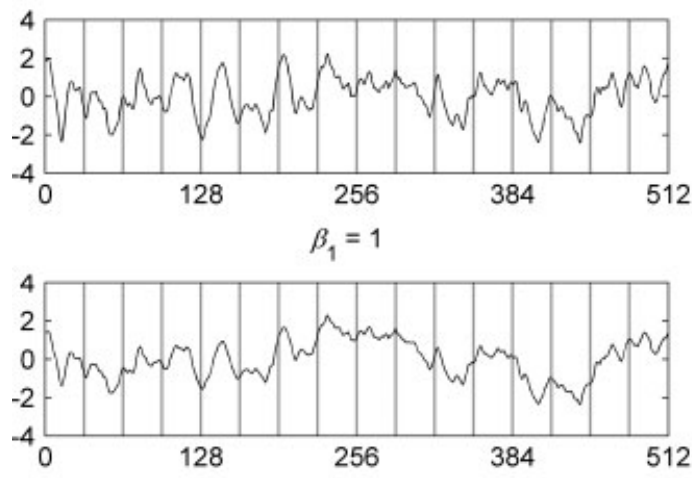

$\beta_{1}=2$

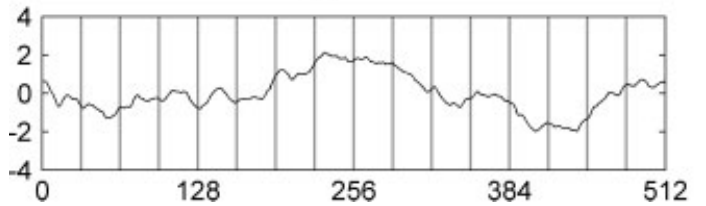

Snow depth fields. Four isotropic fields with mean twodimensional spectral exponents of 1.0 and 4.5 for the low and high frequencies, respectively, and with breaks $\left(T_{b k}\right)$ occurring at scales between 16 and 128 are presented in Figure 12. The spectral exponents of the fields were selected to differ by one with respect to the exponents used to generate the profiles shown in Figure 10. Therefore, a cross-section of the fields would exhibit similar spectral characteristics to the profiles in Figure 10. In the figure, square boxes of side dimensions equal to the corresponding $T_{b k}$ are shown below each field as reference. Similar to the one-dimensional case, the scale at which the break occurs influences the characteristic scales of the fields, with the main features separated by distances comparable with the corresponding $T_{b k}$, and a much smoother pattern of variation for the small scales. The case presented is similar to that observed in the forested environment (Figure 3a), where little anisotropy is observed and the spatial organization of the trees strongly influences the spatial characteristics of snow depth at scales of the order of metres to tens of metres. The location of individual trees and canopy characteristics affect the amount of snowfall intercepted, and as a consequence, influence the size, depth and location of local minima (i.e. tree wells) in the snow cover. Such control explains the similarities between the scaling characteristics of the snow depth and the vegetation height fields in the forested environment.

For the anisotropic case, we explore first the effect of directional dependence of the scale of the break, and second the effect of changes in the low-frequency spectral exponents and the scale of the break simultaneously. These two sub-cases are included to simulate the type of variations in the spectral properties of snow depth observed by Trujillo et al. (2007) in wind dominated environments, as well as in the alpine tundra subarea

(b)

$\beta_{2}=1.5$
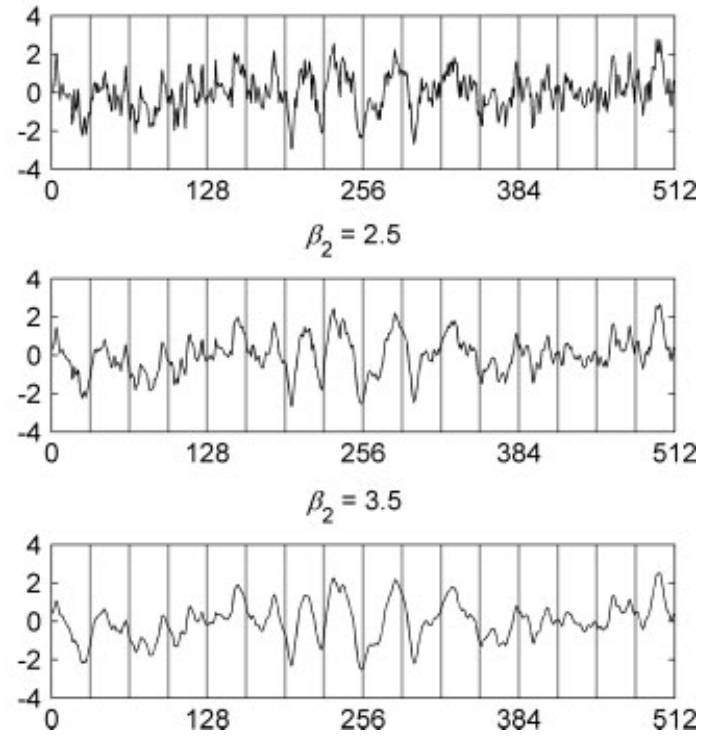

Figure 11. Synthetic profiles with (a) low-frequencies spectral exponents $\left(\beta_{1}\right)$ varying between $0 \cdot 0$ and $2 \cdot 0$, and a constant high-frequencies spectral exponent $\left(\beta_{2}\right)$ of $3 \cdot 5$, and (b) with a constant low-frequencies spectral exponent $\left(\beta_{1}\right)$ of $0 \cdot 0$, and high-frequencies spectral exponents $\left(\beta_{2}\right)$ varying between 1.5 and 3.5 . All of the profiles were generated with $T_{b k}=32$. The grey vertical lines are included as a reference scale and are spaced at a distance of $T_{b k}$ 


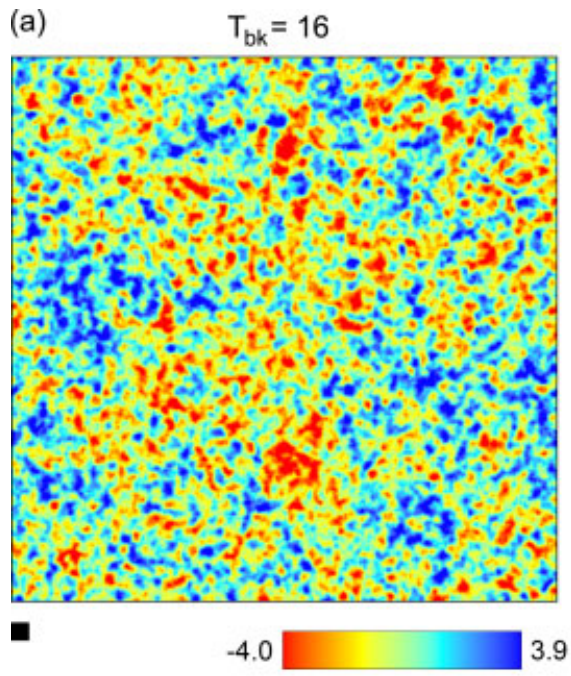

(b) $\quad \mathrm{T}_{\mathrm{bk}}=32$

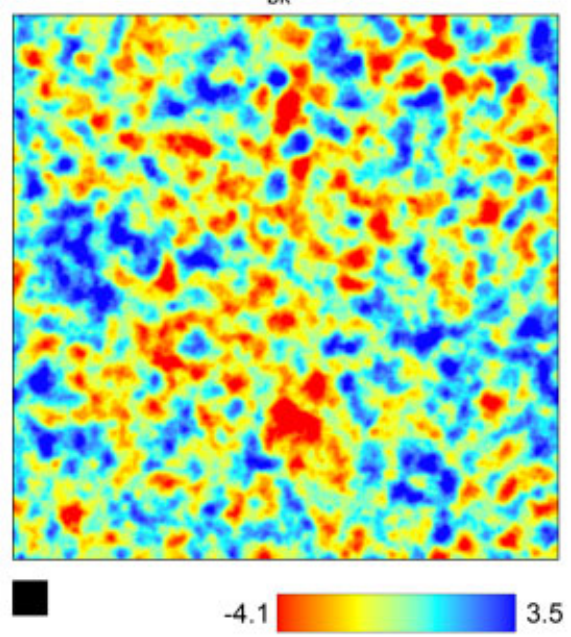

(d)

\section{5}

$\mathrm{T}_{\mathrm{bk}}=128$

$\mathrm{T}_{\mathrm{bk}}=64$
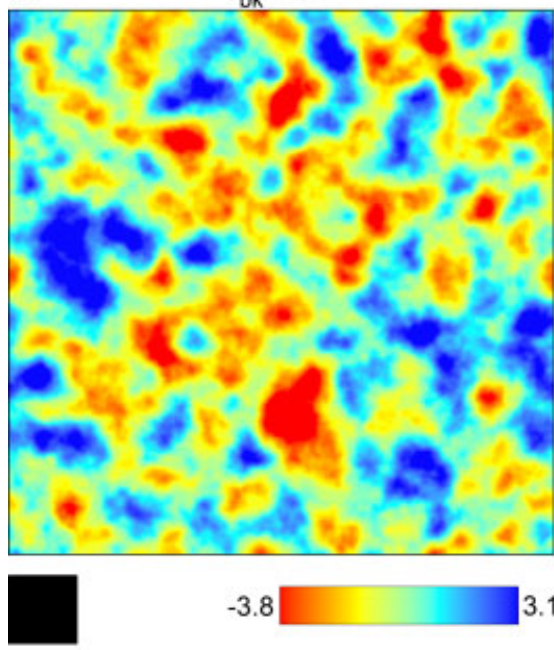

$-3.8$

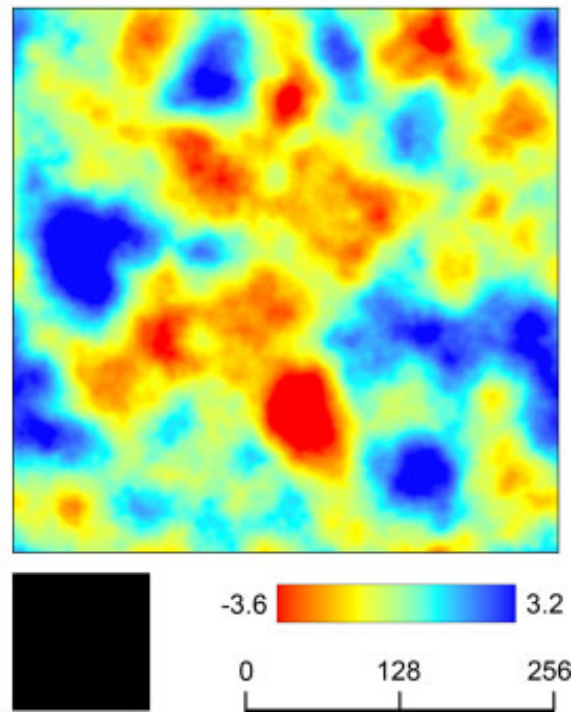

Figure 12. Synthetic fields with two-dimensional low- and high-frequency spectral exponents of 1.0 and 4.5 , respectively, and $T_{b k}$ between 16 and 128. Black square boxes of side $T_{b k}$ are shown below each of the fields as a reference scale

studied here. Our observations indicate that the scale of the break varies from high to low from the predominant wind direction to the perpendicular direction, while the low-frequency exponent varies from low to high from the predominant wind direction to the perpendicular direction.

Figure 13 shows two fields of $512 \times 512$ generated with variations in the scale of the break such that the longer scale break occurs in a predominant direction, and the shorter scale break in a perpendicular direction. The low-frequency and high-frequency one-dimensional spectral exponents were maintained constant for all directions, with $\beta_{1}$ of 0.0 and $\beta_{2}$ of 3.5 . The scale break as a function of direction for each of the fields is indicated by the black ellipse shown at the bottom of each field as a reference scale. The predominant direction (longer scale break) of the fields was selected at $40^{\circ}$ counterclockwise (CCW) from the east direction. The field in Figure 13a exhibits small-scale variability, with longer separation distances between peaks along the predominant direction $\left(T_{b k}=64\right)$. Along the perpendicular direction $\left(T_{b k}=16\right)$, the variability occurs over smaller scales. In Figure 13b, similar characteristics can be observed, however the scale breaks occur at significantly longer spatial scales, with $T_{b k}=128$ along the predominant direction, and $T_{b k}=64$ along the perpendicular direction. Also, because $\beta_{1}$ and $\beta_{2}$ are maintained constant across all directions, the variability of the fields above and below the breaks is similar for all directions, with a weak correlation structure above separations longer than the break, and a strong correlation structure for shorter separations.

Figure 14 shows two synthetic fields generated with directional variations not only in the scale of the break, but also in the low-frequency spectral exponents. The high-frequency spectral exponent was set constant at a value of 2.5 for all directions, similar to the values observed for the snow depth field of the tundra subarea. The field presented in Figure 14a was generated with 
(a)
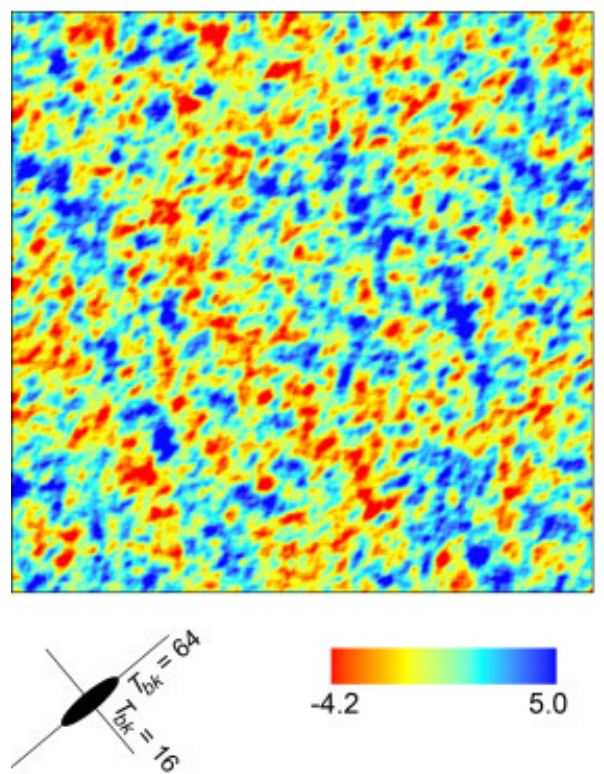

(b)

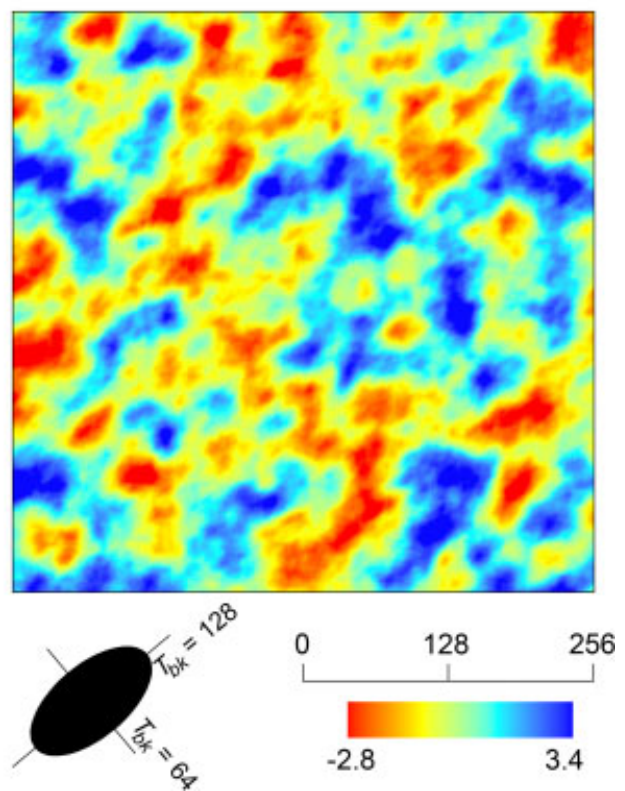

Figure 13. Synthetic anisotropic fields generated with uniform one-dimensional low- and high-frequency spectral exponents of 0.0 and $3 \cdot 5$, respectively, for all directions. The directional variations of $T_{b k}$ are included as a reference scale at the bottom of each field, represented by the black ellipse

(a) $\quad 0.0 \leqslant \beta_{1} \leqslant 0.5, \beta_{2}=2.5$

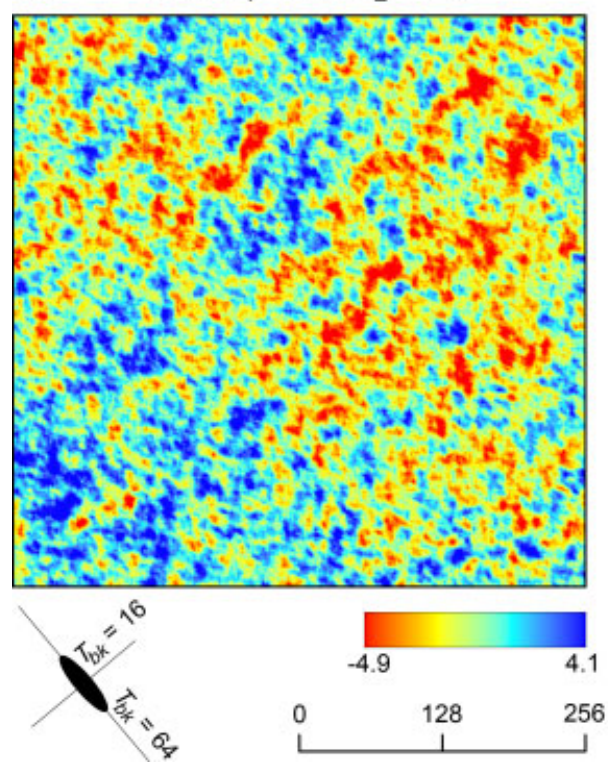

(b) $\quad 0.0 \leqslant \beta_{1} \leqslant 1.5, \beta_{2}=2.5$

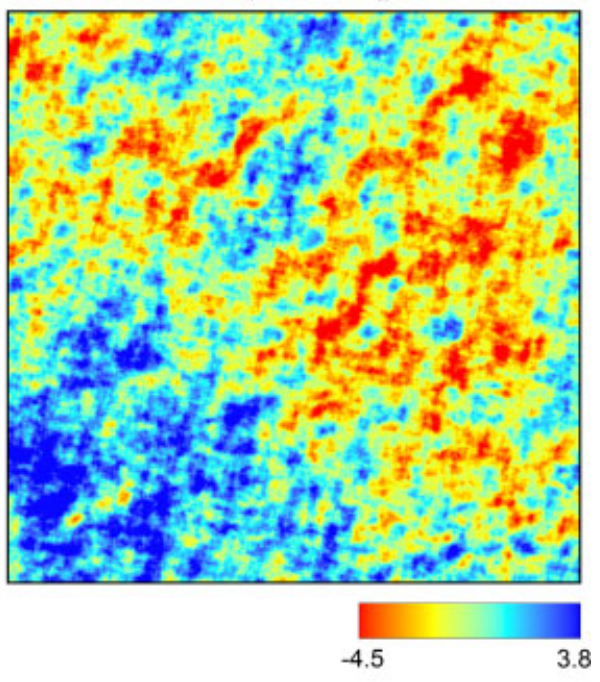

Figure 14. Synthetic anisotropic fields generated with directional variations in $\beta_{1}$ between (a) $0 \cdot 0$ and $0 \cdot 5$, and between (b) $0 \cdot 0$ and $1 \cdot 5$. $\beta_{2}$ was set constant at a value of 2.5 for all directions. The directional variations of $T_{b k}$ are included as a reference scale (black ellipse). A summary of the values of $\beta_{1}, \beta_{2}$ and $T_{b k}$ used to generate the fields is presented in Table III

directional variations in $\beta_{1}$ between 0.0 and 0.5 , and with variation in $T_{b k}$ between 64 for the predominant direction and 16 in the perpendicular direction. The predominant direction of both fields is oriented at $130^{\circ}$ $\mathrm{CCW}$ from the east. The directional variations of the scale break are included as a reference scale at the bottom of Figure 14a, represented by the black ellipse. The field presented in Figure 14b was generated using the same directional variation in $T_{b k}$ as the one used for the field in Figure 14a, but with a wider variation in $\beta_{1}$, with values between 0.0 for the predominant direction, and
1.5 and for the perpendicular direction. A summary of the directional variations of $\beta_{1}$ and $T_{b k}$ used to generate the fields is presented in Table III. Because of these variations, the larger scales exhibit a stronger correlation structure (stronger persistence) along the perpendicular direction $\left(40^{\circ} / 220^{\circ} \mathrm{CCW}\right)$ with respect to that along the predominant direction $\left(130^{\circ} / 310^{\circ} \mathrm{CCW}\right)$, as $\beta_{1}$ goes from 0.5 (Figure $14 \mathrm{a}$ ) or 1.5 (Figure $14 \mathrm{~b}$ ) for the perpendicular direction to 0.0 for the predominant direction. These differences imply that for profiles across the predominant direction, points that are separated by distances larger 
Table III. Summary of the spectral characteristics used to generate the anisotropic fields presented in Figure 14. The angle is measured with respect to the east in the $\mathrm{CCW}$ direction. The two columns for $\beta_{1}$ refer to the corresponding field in the figure

\begin{tabular}{lcccc}
\hline Angle $\left({ }^{\circ}\right)$ & $\beta_{1}(\mathrm{a})$ & $\beta_{1}(\mathrm{~b})$ & $\beta_{2}$ & $T_{b k}$ \\
\hline 130 & 0.00 & 0.00 & 2.5 & 64 \\
175 & $0 \cdot 25$ & 0.75 & 2.5 & 22 \\
220 & 0.50 & 1.50 & 2.5 & 16 \\
265 & 0.25 & 0.75 & 2.5 & 22 \\
\hline
\end{tabular}

than the corresponding scale break exhibit little or no correlation $(\beta=0)$, while for profiles along the secondary direction, points separated by distances larger than the corresponding break exhibit a degree of correlation that is related to the spectral exponent $(0.5$ or 1.5$)$. The correlation structure of the larger scales along intermediate directions lies in between these two bounds.

The fields in Figure 14a and Figure 14b were generated using the same parent processes (the original white noise processes of each of the lines are maintained the same for both of the fields), so the features of the fields are similar, although the magnitudes of the variations are different as the spectral exponents are different. Both fields exhibit similar bands of high values and low values, similar to the ones observed in the snow depth field of the alpine environment (Figure 3b), in which snow drifts and scour areas are formed along a direction that is perpendicular to the predominant wind directions, and with separations between the snow drifts that are dependent on the location of topographic ridges and depressions. However, higher variability can be observed across the perpendicular direction in the field shown in Figure 14a in comparison with the field in Figure 14b, caused by the smaller low-frequency spectral exponent $(0.5$ compared with 1.5).

\section{SUMMARY}

LIDAR snow depths obtained in April 2003 for two adjacent areas $500 \mathrm{~m}$ by $500 \mathrm{~m}$ were analysed to determine scaling characteristics and spatial organization of snow depth in a sub-alpine forest and an alpine tundra environment. Both of the areas present similar topographic characteristics (e.g., slope and aspect), limiting the differences to vegetation characteristics and the influence of wind. The distribution of snow depth in the forested subarea follows a Gaussian distribution, while for the tundra subarea it is negatively skewed. The mean of snow depth increases with elevation in the forest area, while it decreases in the alpine portion. The standard deviation of snow depth in the tundra subarea is greater by a factor of two compared with that of the forested area. The standard deviation of snow depth is relatively constant with elevation below the tree-line, while above the tree-line in the tundra subarea, it shows an overall increase. The two-dimensional correlations of snow depth indicate little spatial memory and quasi-isotropic conditions in the forested area, while they show a marked directional bias that is consistent with the predominant wind directions and the location of topographic ridges and depressions in the tundra subarea. The spectral density functions of the snow depth fields follow a bilinear behaviour with two scale intervals, each characterized by a different spectral exponent. The locations of the scale breaks in the forested area coincide with those of the vegetation height field, while the breaks in the snow depth scaling are displaced towards larger scales in the tundra subarea with respect to those observed in the corresponding vegetation height field.

\section{ACKNOWLEDGEMENTS}

Support for this research was provided by the USDAUSFS Rocky Mountain Research Station under contract 04-JV-11221610-029. Base funding was provided by NASA under contract 02-IA-11221610-104. Some of this work was performed while the second author was on sabbatical leave at the Swiss Federal Institute of Technology (ETH-Z), whose support is gratefully acknowledged.

\section{REFERENCES}

Arnold NS, Rees WG. 2003. Self-similarity in glacier surface characteristics. Journal of Glaciology 49(167): 547-554.

Benson CS. 1982. Reassessment of winter precipitation on Alaska's Arctic slope and measurements on the flux of wind-blown snow. Geophysical Institute Report UAG R-288. Geophysical Institute, University of Alaska, Fairbanks.

Blöschl G. 1999. Scaling issues in snow hydrology. Hydrological Processes 13: 2149-2175.

Blöschl G, Kirnbauer R. 1992. An analysis of snow cover patterns in a small alpine catchment. Hydrological Processes 6: 99-109.

Brown SR. 1987. A note on the description of surface roughness using fractal dimension, Geophysical Research Letters 14(11): 1095-1098.

Cline D, Cold Land Processes working group. 2001. Cold Land Processes field experiment plan, http://www.nohrsc.nws.gov/ cline/clpx.html.

Cline D, Yueh S, Chapman B, Stankov B, Gasiewski A, Masters D, Elder K, Kelly R, Painter TH, Miller S, Katzberg S, Mahrt L. 2008. NASA Cold Land Processes Experiment (CLPX 2002-2003): airborne remote sensing. Journal of Hydrometeorology, in press.

Deems JS, Fassnacht SR, Elder KJ. 2006. Fractal distribution of snow depth from Lidar data. Journal of Hydrometeorology 7: 285-297.

Elder K, Dozier J, Michaelsen J. 1991. Snow accumulation and distribution in an alpine watershed. Water Resources Research 27: $1541-1552$.

Elder K, Michaelsen J, Dozier J. 1995. Small basin modeling of snow water equivalence using binary regression tree methods. Proceedings of Symposium on Biogeochemistry of Seasonally SnowCovered Catchments, IAHS-AIHS and IUGG XX General Assembly. IAHS Publication 228: Boulder, CO; 129-139.

Elder K, Rosenthal W, Davis R. 1998. Estimating the spatial distribution of snow water equivalence in a montane watershed. Hydrological Processes 12(10-11): 1793-1808.

Erickson TA, Williams MW, Winstral A. 2005. Persistence of topographic controls on the spatial distribution of snow in rugged mountain terrain, Colorado, United States. Water Resources Research 41: W04014. DOI: 10·1029/2003WR002973.

Erxleben J, Elder K, Davis R. 2002. Comparison of spatial interpolation methods for estimating snow distribution in the Colorado Rocky Mountains. Hydrological Processes 16: 3627-3649.

Essery R, Pomeroy J, Parviainen J, Storck P. 1996. Sublimation of snow from coniferous forests in a climate model. Journal of Climate 16: $1855-1864$.

Evans BM, Walker DA, Benson DS, Nordstrand EA, Petersen GW. 1989. Spatial interrelationships between terrain, snow distribution and 
vegetation patterns at an arctic foothills site in Alaska. Holarctic Ecology 12: 270-278.

Granger RJ, Pomeroy JW, Parviainen J. 2002. Boundary-layer integration approach to advection of sensible heat to a patchy snow cover Hydrological Processes 16: 3559-3569.

Greene EM, Liston GE, Pielke Sr. RA. 1999. Relationships between landscape, snow cover depletion, and regional weather and climate. Hydrological Processes 13: 2453-2466.

Hosang J, Dettwiler K. 1991. Evaluation of a water equivalent of snow cover map in a small catchment-area using geostatistical approach. Hydrological Processes 5: 283-290.

Huang J, Turcotte DL. 1989. Fractal mapping of digitized images: application to the topography of Arizona and comparison with synthetic images. Journal of Geophysical Research 94(B6): $7491-7495$.

Kang B, Ramírez JA. 2001. Comparative study of the statistical features of random cascade models for spatial rainfall downscaling. Proceedings AGU Hydrology Days 2001, Ramirez JA (ed). Hydrology Days Publications: Fort Collins, CO; 151-164.

Kuchment LS, Gelfan AN. 2001. Statistical self-similarity of spatial variations of snow cover: verification of the hypothesis and application in the snowmelt runoff generation models. Hydrological Processes 15: 3343-3355.

Li L, Pomeroy JW. 1997. Estimates of threshold wind speeds for snow transport using meteorological data. Journal of Applied Meteorology 36: $205-213$.

Liston GE. 1999. Interrelationships among snow distribution, snowmelt, and snow cover depletion: implications for atmospheric, hydrologic, and ecologic modeling. Journal of Applied Meteorology 38(10): $1474-1487$.

Liston, GE. 2004. Representing subgrid snow cover heterogeneities in regional and global Models. Journal of Climate 17: 1381-1397.

Liston GE, Sturm M. 1998. A snow-transport model for complex terrain. Journal of Glaciology 44(148): 498-516.

Lovejoy S, Schertzer D. 1985. Generalized scale invariance in the atmosphere and fractal models of rain. Water Resources Research 21(8): 1233-1240.

Luce CH, Tarboton DG., Cooley KR. 1998. The influence of the spatial distribution of snow on basin-averaged snowmelt. Hydrological Processes 12: 1671-1683.

Luce CH, Tarboton DG., Cooley KR. 1999. Sub-grid parameterization of snow distribution for an energy and mass balance snow cover model. Hydrological Processes 13: 1921-1933.

Mandelbrot B. 1967. How long is the coast of Britain? Statistical selfsimilarity and fractional dimension. Science 156: 636-638.

Mandelbrot B. 1982. The Fractal Geometry of Nature. Freeman: San Francisco.

Mantoglou A. 1987. Digital simulation of multivariate two- and threedimensional stochastic processes with a spectral turning bands method. Mathematical Geology 19(2): 129-149.

Mantoglou A, Wilson JL. 1982. The turning bands method for simulation of random fields using line generation by a spectral method. Water Resources Research 18(5): 1379-1394.

Marsan D, Schertzer D, Lovejoy S. 1996. Causal space-time multifractal processes: Predictability and forecasting of rain fields. Journal of Geophysical Research 101(D21): 26333-26346.

Matheron G. 1973. The intrinsic random function and their applications. Advances in Applied Probability 5: 439-468.

McGinnis GL. 2004. Estimating climate-change impacts on Colorado Plateau snowpack using downscaling methods. The Professional Geographer 45(1): 117-125. DOI: 10·1111/00330124.00062.
Meng H, Ramírez JA, Salas JD, Ahuja L. 1996. Scaling analysis of infiltration at R-5 catchment. Invited Proceedings of the USDA-ARS Workshop on Real World Infiltration, Pingree Park, CO, July 22-25. CWRRI Information Series No. 86; 239-240.

Miller SL. 2003. CLPX-Airborne: Infrared Orthophotography and LIDAR Topographic Mapping, National Snow and Ice Data Center. Digital Media, Boulder, CO.

Over TM. 1995. Modeling space-time rainfall at the mesoscale using random cascades. $\mathrm{PhD}$ dissertation, University of Colorado, Boulder.

Over TM, Gupta VK. 1996. A space-time theory of mesoscale rainfall using random cascades. Journal of Geophysical Research 101(D21): 26319-26332.

Pomeroy JW, Gray DM. 1995. Snowcover accumulation, relocation and management. NHRI Science Report No. 7, National Hydrology Research Institute, Environment Canada: Saskatoon, SK; 134.

Pomeroy JW, Parviainen J, Hedstrom N, Gray DM. 1998. Coupled modelling of forest snow interception and sublimation. Hydrological Processes 12: 2317-2337.

Rodríguez-Iturbe I, Vogel GK, Rigon R, Entekhabi D, Castelli F, Rinaldo A. 1995. On the spatial organization of soil moisture fields. Geophysical Research Letters 22(20): 2757-2760.

Setas M, Rebordão JM. 2000. Modeling anisotropy and fractal twodimensional fields: a tool for image simulation. Optical Engineering 39(6): $1497-1506$.

Shook K, Gray DM. 1994. Determining the snow water equivalent of shallow prairie snowcovers. Proceedings of 51st Eastern Snow Conference, Dearborn, MI; 89-95.

Shook K, Gray DM. 1996. Small-scale spatial structure of shallow snowcovers. Hydrological Processes 10: 1283-1292.

Shook K, Gray DM. 1997. Synthesizing shallow seasonal snow covers. Water Resources Research 33(3): 419-426.

Shook K, Gray DM, Pomeroy JW. 1993. Temporal variation in snowcover area during melt in Prairie and Alpine environments. Nordic Hydrology 24: 183-198.

Tessier Y, Lovejoy S, Schertzer D. 1993. Universal multifractals: theory and observations for rain and clouds. Journal of Applied Meteorology 32(2): 223-250.

Trujillo E, Ramírez JA, Elder KJ. 2007. Topographic, meteorologic, and canopy controls on the scaling characteristics of the spatial distribution of snow depth fields. Water Resources Research 43: W07409. DOI:10·1029/2006WR005317.

Turcotte DL. 1987. A fractal interpretation of topography and geoid spectra on the earth, moon, venus, and mars. Journal of Geophysical Research 92(B4): E597-E601.

Turcotte DL. 1989. Fractals in geology and geophysics. Pure and Applied Geophysics 131(1): 171-196.

Voss RF. 1985. Random fractal forgeries. Fundamental Algorithms for Computer Graphics, NATO ASI Series, Vol. F17, Earnshaw RA (ed). Springer-Verlag: Berlin/Heidelberg; 805-835.

Weitzenkamp B, Sauter T, Kraemer A, Roth R, Schneider C. 2008. Spatial downscaling of snow cover as a tool for projections of snow availability for winter sports in 2030 in the Black Forest using remote sensing and GIS methods. Geophysical Research Abstracts 10: EGU2008-A-06206.

Winstral A, Elder K, Davis R. 2002. Spatial snow modeling of wind-redistributed snow using terrain-based parameters. Journal of Hydrometeorology 3: 524-538.

Xu H, Bailey JO, Barrett EC, Kelly REJ. 1993. Monitoring snow area and depth with integration of remote sensing and GIS. International Journal of Remote Sensing 14(17): 3259-3268. 


\section{APPENDIX}

Spectral generation techniques are useful for the generation of synthetic profiles and fields that exhibit spectral characteristics that are statistically indistinguishable from those observed in the snow depth spectra. Here we introduce modifications of Fourier filtering techniques and of the turning bands method to reproduce the bilinear powerlaw behaviour observed in the profiles and fields of snow depth of the study areas.

\section{Bilinear self-affine profiles}

In order to generate traces with bilinear spectral densities, we use a modified version of the standard Fourier filtering method as indicated below. The following nomenclature is used:

\section{$k$ : wave number}

$k_{b k}$ : wave number at which the scale break occurs

$T_{b k}$ : wave length at which the break occurs, and it is related to the wave number by $N / k_{b k}$, where $N$ is the number of data points in the profile.

The traces are generated as follows:

i. A white noise process is generated as a series of uncorrelated Gaussian random values for the desired number of data points $(N)$.

ii. The complex coefficients of the Fourier transform of the series obtained in step (i) are determined.

iii. The complex coefficients of the Fourier transform of the white noise process are multiplied by a factor of $1 / k^{\beta_{1} / 2}$ for $k=1, \ldots, k_{b k}$, and by a factor of $k_{b k}\left(\beta_{2}-\beta_{1}\right) / 2 / k^{\beta_{2} / 2}$ for $k=k_{b k}+1, \ldots, N / 2$. The complex coefficients for the negative wave numbers correspond to the complex conjugate of the coefficients for the positive wave numbers.

iv. An inverse Fourier transform is performed using the coefficients obtained in (iii). The power spectrum of the resulting series will follow a bilinear power law relationship with a scale break at $k_{b k}$.

Minimum and maximum absolute errors for the lowfrequency exponent of the profiles in Figures 10 and 11 are 0.01 and 0.22 , respectively, while the mean absolute error for all the profiles is 0.05. For the high-frequency exponent, the minimum and maximum absolute errors are 0.00 and 0.10 , respectively, while the mean absolute error is 0.05 .

\section{Bilinear self-affine fields}

Case one: Isotropic fields. Similar to the methodology used for generating linear and bilinear profiles, the Fourier filtering technique can be extended in order to generate synthetic isotropic fields, i.e. fields in which all directions in the $x-y$ plane are equivalent, with a bilinear power spectrum with two-dimensional exponents $\beta_{1}$ and $\beta_{2}$.
The fields can be generated as follows:

i. A random white noise field $\sim N(\mu, \sigma)$ is generated for the desired number of data points $(N$ by $N)$.

ii. The complex coefficients of the two-dimensional Fourier transform of the field obtained in (i) are determined.

iii. The complex coefficients of the two-dimensional Fourier transform of the white noise field are multiplied by a factor of $1 / k^{\beta_{1} / 2}$ for $k \leq k_{b k}$, and by a factor of $k_{b k}{ }^{\left(\beta_{2}-\beta_{1}\right) / 2} / k^{\beta_{2} / 2}$ for $k>k_{b k}$, with $k=$ $\left(k_{x}^{2}+k_{y}^{2}\right)^{1 / 2}$.

iv. An inverse Fourier transform is performed using the coefficients obtained in (iii). The mean twodimensional power spectrum of the resulting series will follow a bilinear power law relationship with a scale break at $k_{b k}$.

Minimum and maximum absolute errors for the lowfrequency exponent of the isotropic fields in Figure 12 are 0.07 and 0.13 , respectively, while the mean absolute error is $0 \cdot 10$. For the high-frequency exponent, the minimum and maximum absolute errors are 0.00 and 0.03 , respectively, while the mean absolute is 0.01 .

Case two: Anisotropic fields. Bilinear anisotropic fields were generated using a modification of the turning bands method (TBM) (Matheron, 1973; Mantoglou and Wilson, 1982). In two-dimensional space, the TBM transforms the simulation of a two-dimensional realization into the sum of a series of one-dimensional realizations. In the isotropic case, the generations of the one-dimensional (line) realizations are performed along several lines in the unit circle, using a unique one-dimensional covariance function (or power spectral density function) that corresponds to a given two-dimensional covariance function. Then, the value of the two-dimensional process is obtained as a weighted sum of the corresponding values of the line processes. For a particular point in the twodimensional space, the corresponding one-dimensional values are assigned by orthogonally projecting the points of the line realization, reason for which the method is named 'turning bands', as the projection of the line process appears as a series of bands that rotate according to the direction of each of the lines. Further details of the projection methodology are not included here as this methodology has been described extensively in several related publications (Mantoglou and Wilson, 1982; Mantoglou, 1987; Setas and Rebordão, 2000). The method assumes that the field to be simulated is second-order stationary and isotropic, and that at each point the values are normally distributed and have zero mean.

More recent applications of the methodology have been developed for anisotropic covariance functions (Mantoglou, 1987; Setas and Rebordão, 2000). Anisotropy can be simulated by distributing the lines around the unit circle along directions sampled from a non-uniform probability density function. An alternative approach for simulating anisotropy consists of making the spectral density 
function (or covariance function) of the one-dimensional process dependent on direction. The latter approach is the one implemented in this study, varying the spectral exponents and scale of the breaks as a function of direction. The line processes are generated following the procedure described earlier. The methodology is applied uniformly distributing the desired number of lines along the unit circle similar to Mantoglou and Wilson (1982) and Mantoglou (1987). In this way, the anisotropy in the spectral characteristics can be provided as an input in which the location of the scale break and the spectral exponents can be specified for each of the lines. The method was applied using the centre of the grid as the origin for the generation. To ensure continuity of the line processes, and as collinear directions have equivalent spectral properties, the dimension of the line processes was selected to be two times the side dimension of the square grid, and the origin was set to coincide with the midpoint of the line. For example, if the desired grid size is $N \times N$, the dimensions of line processes is $2 N$ and the origin is located at point $N$. These characteristics condition the lower bound for the spacing of the line processes to be $\sqrt{2} / 2$ times the spacing of the grid. Such condition ensures that the length of the lines is greater than or equal to the length of the diagonal of the grid.

Given the conditions stated above, the methodology can be implemented as follows:

i. Define the size of the grid $(N \times N)$, spacing of the grid $\left(\Delta_{g}\right)$, spacing of the line process $\left(\Delta_{l}\right)$, angular separation between the lines (e.g., degrees), and spectral properties for each of the lines $\left(\beta_{1}, \beta_{2}\right.$ and $T_{b k}$ ). Note that defining the angular separation is equivalent to defining the number of lines $(L)$.

ii. A line process is generated for each direction using the corresponding spectral characteristics provided as input. This step is performed using the procedure described earlier. $k_{b k}$ can be determined by approximating the result from dividing the total length of the desired profile by $T_{b k}$ to the closest integer.

iii. The value corresponding to each of the points in the grid is obtained as (Mantoglou and Wilson, 1982)

$$
z_{s}\left(\mathbf{x}_{N}\right)=\frac{1}{\sqrt{L}} \sum_{i=1}^{L} z_{i}\left(\mathbf{x}_{N} \cdot \mathrm{u}_{i}\right)
$$

where $z_{s}\left(\mathbf{x}_{N}\right)$ is the realization of the two-dimensional process for the position $\mathbf{x}_{N}, z_{i}\left(\mathbf{x}_{N} \cdot \mathbf{u}_{i}\right)$ is the corresponding realization of the one-dimensional process for line $i$, and $\mathbf{x}_{N} \cdot \mathbf{u}_{i}$ is the projection of the position vector $\mathbf{x}_{N}$ onto the unit vector $\mathbf{u}_{i}$ (directional vector for line $i$ ). The subscript $s$ indicates 'synthetic'.

Minimum and maximum absolute errors for the lowfrequency exponent of the isotropic fields in Figures 13 and 14 are 0.03 and 0.23 , respectively, while the mean absolute error is 0.09 . For the high-frequency exponent, the minimum and maximum absolute errors are 0.01 and $0 \cdot 17$, respectively, while the mean absolute is 0.07 . 